\title{
Recent Research Progress in Surface Ligand Exchange of PbS Quantum Dots for Solar Cell Application
}

\author{
Hyung Ryul You ${ }^{1,+} \oplus^{\infty}$, Jin Young Park ${ }^{1,+}{ }^{-}$, Duck Hoon Lee ${ }^{1}$, Younghoon Kim ${ }^{2, *}$ and \\ Jongmin Choi ${ }^{1, *}$ \\ 1 Department of Energy Science and Engineering, Daegu Gyeongbuk Institute of Science \& \\ Technology (DGIST), Daegu 42988, Korea; vogudfuf@dgist.ac.kr (H.R.Y.); wlsdud2403@dgist.ac.kr (J.Y.P.); \\ ldh4440106@hanmail.net (D.H.L.) \\ 2 Division of Energy Technology, Daegu Gyeongbuk Institute of Science \& Technology (DGIST), \\ Daegu 42988, Korea \\ * Correspondence: younghoon.kim@dgist.ac.kr (Y.K.); whdals1062@dgist.ac.kr (J.C.) \\ + The authors contributed equally.
}

Received: 9 January 2020; Accepted: 27 January 2020; Published: 2 February 2020

\begin{abstract}
Colloidal quantum dots (CQDs) are considered as next-generation semiconductors owing to their tunable optical and electrical properties depending on their particle size and shape. The characteristics of CQDs are mainly governed by their surface chemistry, and the ligand exchange process plays a crucial role in determining their surface states. Worldwide studies toward the realization of high-quality quantum dots have led to advances in ligand exchange methods, and these procedures are usually carried out in either solid-state or solution-phase. In this article, we review recent advances in solid-state and solution-phase ligand exchange processes that enhance the performance and stability of lead sulfide ( $\mathrm{PbS}$ CQD solar cells, including infrared (IR) CQD photovoltaics.
\end{abstract}

Keywords: quantum dots; ligand exchange; solar cell; PbS

\section{Introduction}

Even though the world has been dominated by the prevalence of fossil fuels, their limited reserves and associated environmental issues make it difficult to fulfill the ever-growing global energy exigencies, and the development of renewables is essential to meet these rapidly expanding energy demands. Among various renewables, solar energy has orders of magnitudes with more potentials compared to other renewables or fossil fuels, and the solar cell is one of the representative routes toward utilizing solar energy. Crystalline silicon solar cells are well-known as commercialized photovoltaics due to their outstanding power conversion efficiency $(P C E)$ and stability; however, they usually require complicated manufacturing processes and high fabrication costs. Considering these concerns, the development of solution-processed solar cells has been highly required from researchers.

Colloidal quantum dots (CQDs) are small-sized semiconducting nanoparticles, wherein the size of nanoparticle is smaller than its exciton Bohr radius, showing the quantum confinement effect, and CQDs have been considered as promising candidates to realize efficient solution-processed solar cells due to their tunable optoelectrical characteristics according to their size and outstanding ambient stability [1-3]. Beyond these merits, the multiple exciton generation (MEG) phenomenon in CQDs can be a breakthrough to improve the performance of CQD solar cells $[4,5]$. The movement of electrons and holes in CQDs is confined along the crystalline direction, resulting in quantized energy level states. In this condition, the hot-carrier energy is maintained without phonon releasing, and this energy can be transferred to other carriers, leading to MEG. While the maximum theoretical PCE 
of a single $\mathrm{p}-\mathrm{n}$ junction solar cell is known as $33.7 \%$ with the materials having a $1.34 \mathrm{eV}$ bandgap (Shockley-Queisser limit), this ideational limit can be improved up to $44 \%$ with the aid of MEG. Additionally, the size-dependent bandgap of CQDs offers a chance to harvest the infrared (IR) region of the solar spectrum. Since the light harvesting of representative photo-active materials, such as crystalline silicon and metal halide perovskite materials, are limited under $1100 \mathrm{~nm}$ wavelength, the large-size (smaller bandgap than $1.1 \mathrm{eV}$ ) CQDs are fascinating for realizing efficient tandem optoelectronics utilizing the IR light regions [6,7]. Among the various CQDs, lead sulfide (PbS) CQDs are generally used components for photovoltaics due to their wide light absorption window.

Generally, CQDs are stabilized by organic surface ligands (i.e., oleic acid, oleylamine, etc.) to produce solubility in non-polar solvents and prevent CQD aggregation. However, long alkyl chain ligands can disturb the charge transport within the CQD thin films, resulting in poor device performance. On the other hand, the complete removal of surface ligands can produce surface defect sites and dot fusing, resulting in reduced device performances and quantum confinement effects. Therefore, the development of ligand exchange processes has been studied to replace the long-chain ligands with much shorter or atomic ligands leading to the improved functionality of CQDs in solar cell applications. Herein, we review recent advances in ligand exchange procedures, as well as their applications in $\mathrm{PbS}$ CQD solar cells.

\section{Solid-State Ligand Exchange}

Ligand exchange is mainly classified as two different processes, namely, the solid-state and solution-phase ligand exchange procedures. Firstly, the ligand exchange procedures are mainly conducted in solid-state, which involves the following four steps (Figure 1): (i) fabrication of as-cast CQD thin films on the target substrate by spin-coating the CQD solution dissolved in a non-polar solvent; (ii) introduction of the polar solvent, including short organic ligands, such as 1,2-ethanedithiol (EDT) or mercaptopropionic acid (MPA) on the CQD films; (iii) soaking the CQD films with the polar solvent, including short organic ligands during optimized times, as well as the elimination of the solution by following spin-coating; (iv) washing the CQD film by the casting of neat polar solvents to remove exchanged long ligands and excess new short ligands. Generally, approximately $40 \mathrm{~nm}$-thick CQD films are produced from the first step of the solid-ligand exchange process [8,9], and the thickness can be controlled by repeating the process based on a layer-by-layer approach for achieving the desired thickness in solar cells with optimal light harvesting. Among the various studies on CQD photovoltaics produced from solid-state ligand exchange processes, some of the research progress that has been reported so far are summarized in the sections below.

\section{Solid phase ligand exchange}
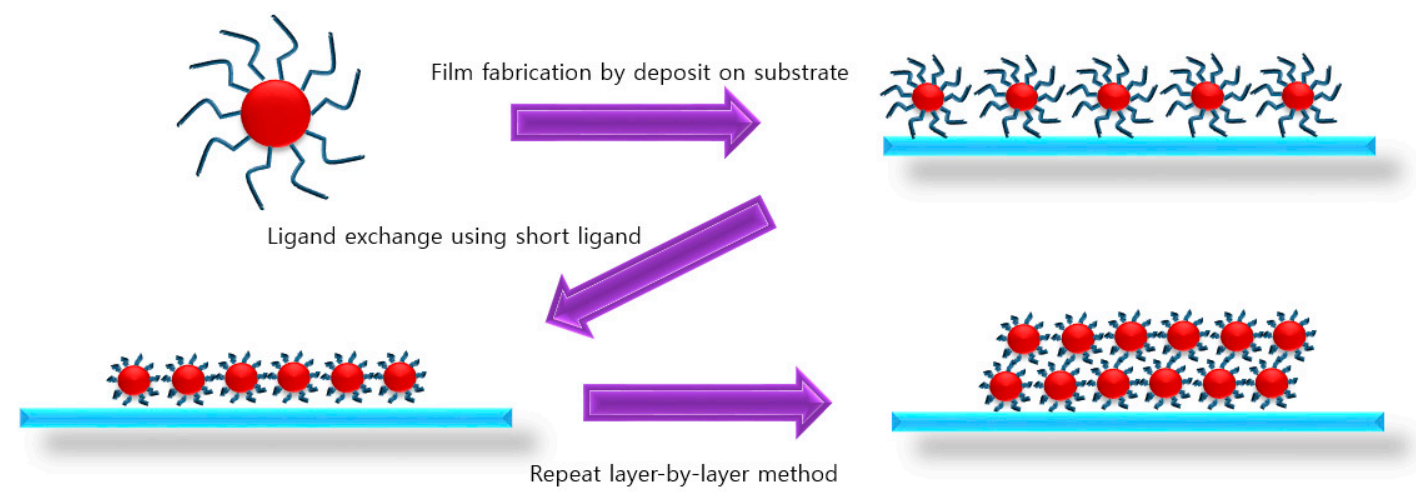

Figure 1. Schematic of solid-state ligand exchange and film fabrication. Initially, colloidal quantum dots (CQDs) were deposited on the substrate, and then ligand-exchanged using short organic ligands. CQD film fabrication is completed by repeating this method. 


\subsection{Air-Stable PbS CQDs via Solid-State Ligand Exchange Process}

High device performance and stability are essential requirements to realize efficient solar cells. Even though PbS CQDs had been considered as promising candidates to make breakthroughs in solar cells, the initial ambient stabilities of PbS CQD photovoltaics (PVs) were poor, and their performance had to be measured under $\mathrm{N}_{2}$-filled inert conditions. When PbS CQDs were exposed to air, oxidized layers could be formed at the CQD surface, and these layers can cause poor electrical conductivity resulting in decreased device performance. To overcome the poor air stability of PbS CQD PVs, intensive studies to prevent the surface of PbS CQDs from oxidization had been conducted by using specific substances for ligand exchange or control the surface of PbS CQDs. Sargent et al. reported $3 \mathrm{~nm}$-sized PbS CQD PVs fabricated via the solid-state ligand exchange process using ethanedithiol (EDT) as a short-chain ligand. The PbS CQD PVs were stable for $63 \mathrm{~h}$, and the performance measurement could also be carried out in ambient conditions. The stability of PbS CQDs are mainly governed by the magnitude of oxidation, and Sargent et al. revealed that the oxidation species of PbS CQDs are quite different from their crystal sizes [11]. For larger-sized PbS CQDs within the range of $4 \mathrm{~nm}$ to $10 \mathrm{~nm}$ diameter, $\mathrm{PbSO}_{4}$ is mainly observed on the PbS CQD surface after oxidation, whereas, $\mathrm{PbSO}_{3}$ is the principal oxidation product for oxidized smaller-sized PbS CQDs with diameters less than $3 \mathrm{~nm}$. $\mathrm{PbSO}_{3}$ and $\mathrm{PbSO}_{4}$ states in $\mathrm{PbS}$ are well-known as trap states located under the conduction band edge with $-0.1 \mathrm{eV}$ and $-0.3 \mathrm{eV}$, respectively. The small dots $-0.1 \mathrm{eV}$ below the level of the conduction band edge are relatively shallow, which show effects that increase the carrier lifetime [12,13]. However, the large dots $-0.3 \mathrm{eV}$ below the conduction level of the band edge are relatively deep and result in catastrophic recombination of the carriers. The different oxidation species of PbS CQDs depending on their sizes are originated from their different facet geometries $[14,15]$. In contrast, the small dot surfaces are almost passivated with the ligand, and spatial hindrance effects prevent PbS CQDs from oxygen (Figure 2). This is the first demonstration of solution-processed CQD PVs showing stability in ambient conditions. Later, the first certified PbS CQD solar cell exhibiting 3\% of PCE was also fabricated using EDT-based small-size PbS CQDs and reported [16].

\subsection{Carrier Mobility of PbS CQDs Depending on Ligand Species}

Carrier mobility in the CQD thin film is also one of the important factors that determine the performance of the CQD solar cell, and many studies have been performed to improve carrier transport characteristics in PbSe and PbS CQD thin films. Prior to this study, 1,4-benzenedithiol (BDT) and EDT were generally used as short-chain ligands for replacing the native ligands of as-cast $\mathrm{PbSe}$ and $\mathrm{PbS}$ CQD thin film. These short-chain ligands enabled improved carrier transport in the PbSe and PbS CQD thin film. However, these ligands still had insufficient properties for application to optoelectronic and photovoltaic devices, because the S-S distance is still $\sim 6.4 \AA$ scale in the case of PbS CQD with BDT ligands [17]. In the thiol-treated case, the $\sim 100 \mathrm{~nm}$ scale carrier diffusion length results in low quantum efficiency. Additionally, BDT- and EDT-treated PbSe and PbS CQD thin films are vulnerable to oxidation, which results in the ligand loss of CQDs $[8,18,19]$. In 2010, Law et al. used carboxylic acid-based short-chain organic ligands to overcome the issues originating from BDT- and EDT-based solid-state ligand exchange processes [20]. An FET device was fabricated to measure the carrier transport characteristics of carboxylic acid ligand-treated PbSe and PbS CQD thin film. These PbSe and PbS CQD thin films showed not only good carrier transport characteristics but also better stability in ambient conditions. In BDT- and EDT-treated CQD thin films, carrier mobility is immediately decreased when exposed in ambient conditions. However, carboxylic acid ligand-treated $\mathrm{PbSe}$ and $\mathrm{PbS}$ CQD thin films showed increased mobility in ambient conditions for $72 \mathrm{~h}$ (Figure 3). This phenomenon, which also originated from a two-stage oxidation mechanism, resulted in PbSe and PbS CQD thin films showing 10-30 times higher carrier mobility compared to the previous PbSe and PbS CQD thin film. The initial adsorption of water and oxygen provides better surface passivation, reducing the surface trap states and increasing the carrier mobility. Over time, gradually-hydrolyzed carboxylate ligands enable the penetration of oxygen to PbSe and PbS CQDs, leading to a decrease in carrier mobility. 
Herein, for the CQD FET, it is revealed that the carboxylic acid ligand-treated PbSe and PbS CQD thin film enhances carrier transport characteristics with increased stability in ambient conditions. From this, it is expected that adequate carboxylic acid-based ligand treatment for the PbSe and PbS CQD thin film, rather than the BDT or EDT, could lead to further enhancement of the PbSe and PbS CQD solar cell performance.
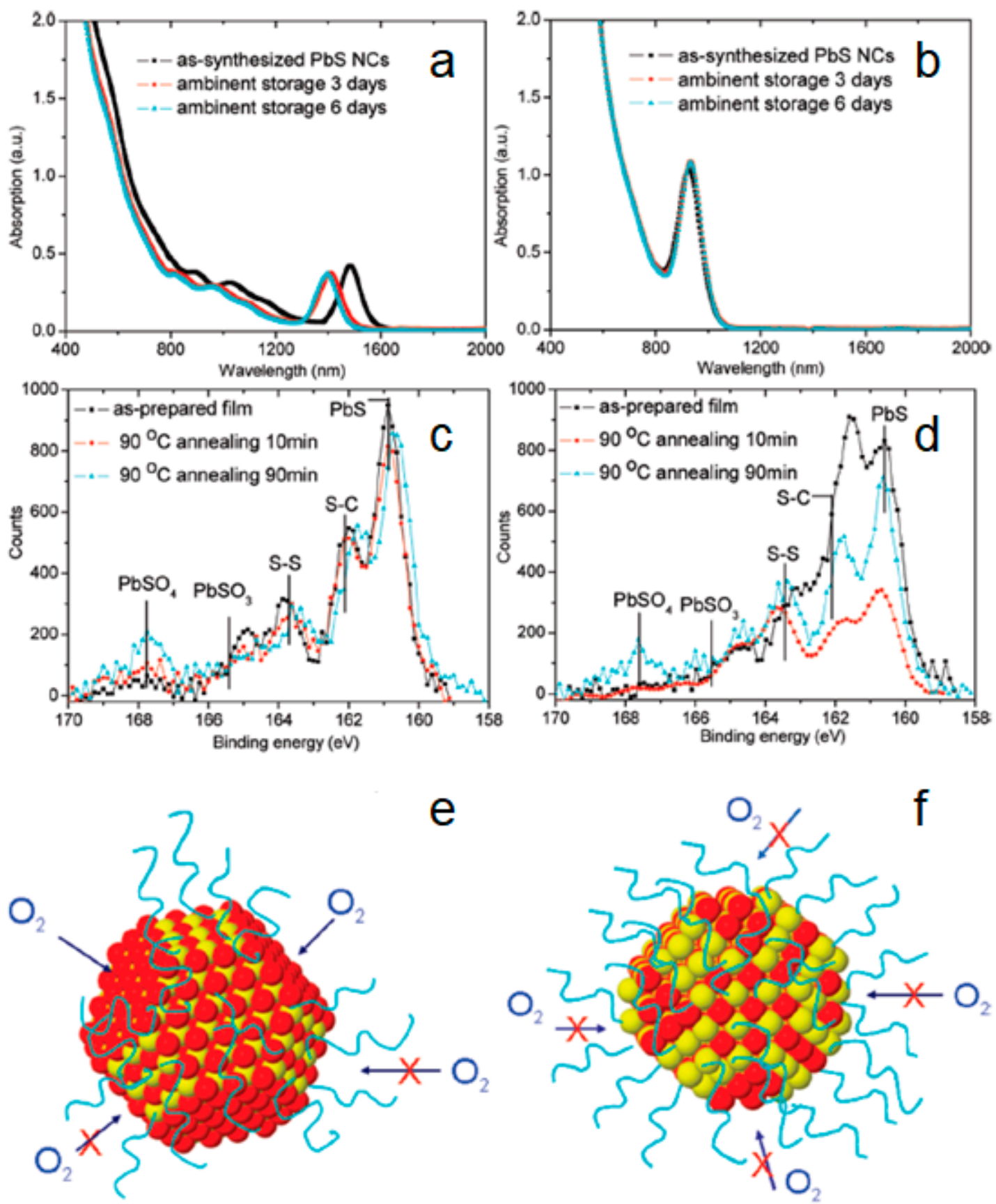

Figure 2. Comparison of large- (a-c) and small-sized (d-f) lead sulfide (PbS) CQDs (a). (b) Absorption change of large and small PbS CQDs dispersed in octane solution under ambient as a function of storing time. (c,d) XPS analysis of large and small PbS CQDs showing S 2p spectra of as-fabricated film (black), annealed-film at $90^{\circ} \mathrm{C}$ in air for $10 \mathrm{~min}$ (red) and for $90 \mathrm{~min}$ (cyan). (e,f) Schematic of large and small $\mathrm{PbS}$ CQDs described by red and yellow spheres, and cyan tails connected to sulfur atoms. Small $\mathrm{PbS}$ NCs are more resistant to oxidation compared to large PbS NCs. Reprinted from reference [10]. Copyright 2010 American Chemical Society. 

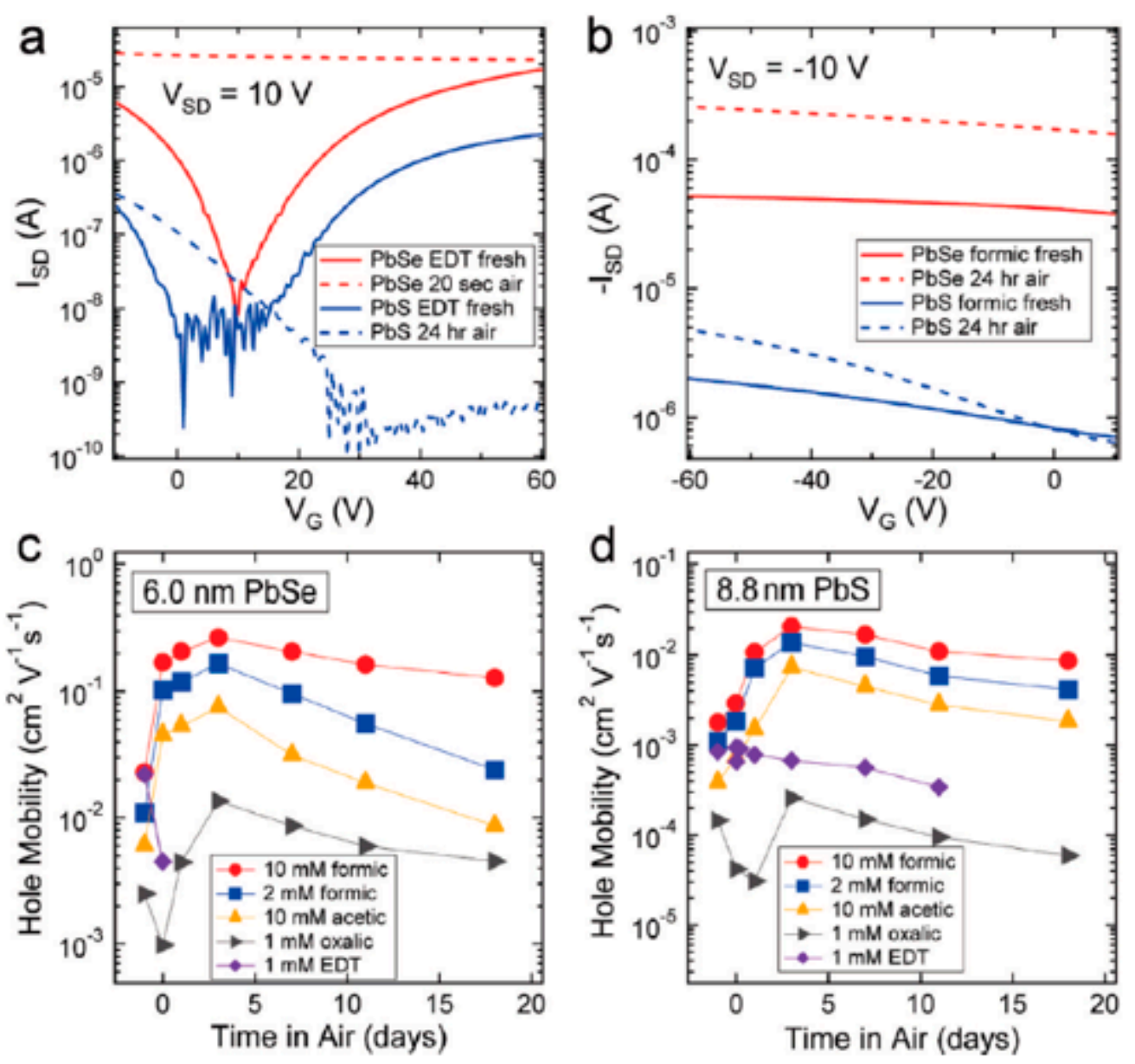

Figure 3. Electrical performance of PbSe and PbS QD field-effect transistors (FETs) according to air exposure. (a) Transfer curves $\left(\mathrm{I}_{\mathrm{D}}-\mathrm{V}_{\mathrm{G}}\right)$ of ethanedithiol (EDT)-treated PbSe and PbS FETs. (b) Transfer curves of formic-treated PbSe and PbS FETs. (c) Hole mobility changes over time of carboxylate-capped PbSe FETs in air. (d) Hole mobility changes over time of carboxylate-capped PbS FETs in air. Reprinted from reference [20]. Copyright 2010 American Chemical Society.

\subsection{Halide Ligand to Eliminate Trap States}

When CQD surfaces are insufficiently passivated, CQDs with a high surface-area-to-volume ratio show an increase of trap state density near their midgaps. These trap states can promote charge recombination, and the elimination of trap states at their midgap is essential to realize highly efficient CQD PVs [21]. This goal can be achieved by robust organic-inorganic hybrid passivation via solid-state ligand exchange processes using mercaptopropionic acid (MPA) and $\mathrm{CdCl}_{2}$ [22]. The MPA organic ligands cannot cover whole inter-atom trenches on the $\mathrm{Pb}$-abundant surface due to the steric issue and lack of appropriate coordination numbers. Halide inorganic ligands are small enough to fill the trenches on hard-to-access sites, and are therefore used to complement the insufficient MPA passivation strategy as organic-inorganic hybrid passivation. The density of the midgap trap state in hybrid-passivated PbS CQD was observed to be $2 \times 10^{16} \mathrm{~cm}^{-3} \mathrm{eV}^{-1}$, indicating a five times lower value than that of conventional organic- and inorganic-only PbS CQDs. Grazing-incidence small-angle $X$-ray scattering (GISAXS) shows the average value of the inter-center spacing of unexchanged and oleic acid-capped PbS CQDs that is measured to be $4.4 \mathrm{~nm}$, which is coherent with the nm-scale spacing originated from bulk oleic acid. The inter-dot spacing was reduced to $3.4 \mathrm{~nm}$ when employed with the short MPA ligands. Although the organic content of the PbS CQDs was removed after the solid-state ligand exchange using inorganic ligands, the resultant PbS CQD thin films showed the retained inter-dot spacing of $4.4 \mathrm{~nm}$, which is consistent with that of the unexchanged PbS CQD thin 
films [20]. These findings confirm the importance of the bidentate organic crosslinker during solid-state ligand exchanges to achieve PbS CQD densification. As a result, the hybrid-passivated PbS CQD PV showed a certified PCE of $7.0 \%$ owing to the above-mentioned merits.

\subsection{Solvent-Polarity-Eengineered Halide Passivation}

Unsaturated dangling bonds induced from the large surface-to-volume ratio of CQD materials can introduce undesired trap states within the bandgap of CQDs. Atomic halide ligands have been recently used for PbS CQD surface passivation due to their high electronegativity and significant improvement of air stability of PbS CQD solids [23-25]. Among halides, Sargent et al. reported solution-processed iodine treatment on PbS CQDs showing improved surface passivation. By increasing diffusion length, the thickness of the light absorption layer in a device can be increased without affecting the charge extraction. A certified PCE record of $9.9 \%$ was achieved by this approach [26]. However, iodine can cause uncontrollable CQD fusing due to its highly reactive characteristic. Other studies reported that more iodine, using methylammonium iodide (MAI) as a milder iodine source, can be introduced into the PbS CQD surface without the damaging effects of fusion. For the solution-phase ligand exchange of oleic acid-capped PbS CQDs, a cosolvent strategy was adopted to create a mixture of miscible solvents, which were toluene and dimethylformamide (DMF) [27]. The cosolvent strategy for tuning the solvent polarity simultaneously enables the dispersion of MAI and PbS CQDs. Therefore, OA-capped PbS CQDs are reacted with iodide anions solvated in DMF, allowing the combination of iodide anion ligands on the PbS CQD surface in the solution-phase. The solution-phase ligand exchange can be explained by the equation: $\mathrm{PbS}\left[\mathrm{Pb}(\mathrm{OA})_{2}\right]+2 \mathrm{MA}^{+} \mathrm{I}^{-} \rightarrow \mathrm{PbS}\left(\mathrm{PbI}_{2}\right)+2 \mathrm{MA}^{+} \mathrm{OA}^{-} .{ }^{1} \mathrm{H}$ NMR spectroscopy measurements show new peaks that are consistent with the formation of an iodide ligand shell that dynamically interacts with the $\mathrm{OA}^{-}$removed from the vacant site. MAI solution pretreatment results in the replacement of $\mathrm{OA}^{-}$with approximately $20 \%$ to iodide, which is three times higher than that of $\mathrm{I}_{2}$ treatment, confirmed by quantitative measurements of $\mathrm{X}$-ray photoelectric spectroscopy (XPS) (Figure 4d). After the treatment of MAI and $\mathrm{I}_{2}, \mathrm{PL}$ quantum yield (QY) increases up to $15 \%-29 \%$ and $19 \%$, respectively, and the improvement of iodide incorporation leads to enhanced surface passivation (Figure 4a,b). Additionally, MAI pre-treatment improves the colloidal stability of $\mathrm{PbS}$ CQDs by the partial elimination of the oleate ligands. The partial removal of ligands, indicating the remaining oleates, is important to stabilize PbS CQDs in octane. When all of the ammonium ligands are completely removed through the above procedures, Au electrodes are employed on the top of the final PbS CQD thin films to allow the ohmic contact. As a result, 10.6\% PCE in PbS CQD solar cells was achieved by improved surface passivation, and a series of results contributed to the surface engineering of PbS CQDs, such as using stoichiometry tuning and surface doping. 

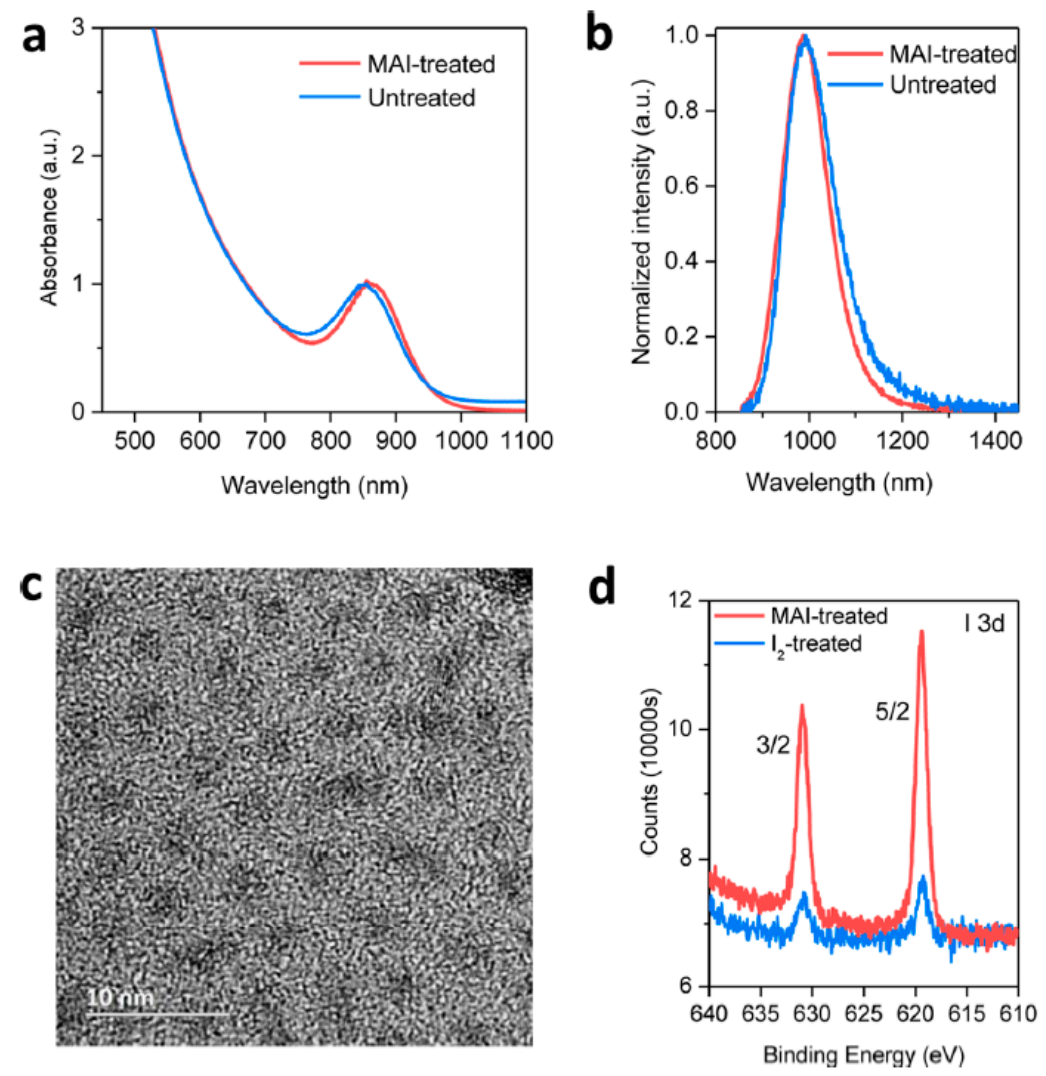

Figure 4. Characterization of PbS CQDs with different treatments. (a) Absorption spectra of PbS CQDs depending on methylammonium iodide (MAI) treatment. (b) Photoluminescence spectra of PbS CQDs depending on MAI treatment. (c) High-resolution transmission electron microscopy (HR-TEM) image of MAI-treated PbS CQDs showing no fusion. (d) Quantitative measurements by XPS. I 3D peak of both $\mathrm{I}_{2}$-treated and MAI-treated PbS CQDs, showing large enhancement of I-incorporation for the MAI case. Reprinted from reference [27]. Copyright 2016 American Chemical Society.

\section{Solution-Phase Ligand Exchange}

Even though solid-state ligand exchange procedures have been widely used to fabricate PbS CQD PVs $[7,23,28-33]$, several limitations still remain. For example, partial loss of a ligand can take place during the solid-state ligand exchange process by a protic solvent effect. Additionally, to produce a thick CQD film using solid-state ligand exchanges for sufficient light harvesting, layer-by-layer approaches requiring a long fabrication time and a large number of materials should be carried out. Solution-phase ligand exchange using aprotic solvents has been recently developed to address these issues (Figure 5) [34]. This approach relies on creating a colloidal dispersion in a polar solvent after ligand exchange resulting from the replacement of long-chain organic ligands to short halide ligands. The formation of surface defects on CQDs during ligand exchange can be suppressed by this method, allowing for the elimination of multiple deposition steps, which are necessary to the previous layer-by-layer method. The best device performances in CQD PVs reported so far have also been achieved by the solution-phase ligand exchange approach. Some recent impressive achievements in $\mathrm{PbS} C Q D \mathrm{PVs}$ fabricated using the solution-phase ligand exchange are described in the sections below. 


\section{Solution phase ligand exchange}

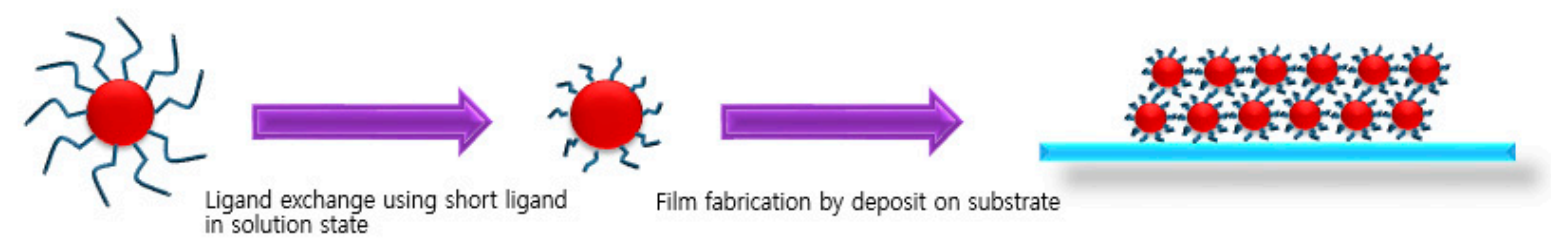

Figure 5. Schematic of the solution-phase ligand exchange and film fabrication. Ligands of CQDs are exchanged in the solution-phase first. After that, CQD films can be fabricated just by spin-coating the CQD inks on the substrate.

\subsection{Directly Usable PbS CQD Inks by Solution-Phase Ligand Exchange}

Inorganic ligands, such as halide anions, have significantly developed PbS CQD PVs [35-37]; however, such approaches that have been conducted by solid-state ligand exchange require a large amount of material and are time consuming. Therefore, solution-phase ligand exchange using halide can provide numerous merits. Sargent et al. reported PbS CQD PVs based on a halide ligand-capped PbS CQD ink prepared via the solution-phase ligand exchange [34]. To produce the PbS CQD ink, the PbS CQDs dispersed in a nonpolar solvent such as octane, and iodide salts dissolved in dimethylformamide (DMF) are vortexed vigorously. They are then kept static until the phase separation. After eliminating the top octane solvent, the PbS CQDs are washed using a polar solvent to eliminate residual organic debris. Finally, toluene is added to precipitate PbS CQD, and after following centrifugation and redispersion in butylamine, PbS CQD ink can be obtained (Figure 6a). This enables a direct and simple fabrication of thick PbS CQD film with an approximately $300 \mathrm{~nm}$ thickness, as well as minimize waste of materials (Figure 6b,c). The resultant PbS CQD films exhibited an $n$-type characteristic which is suitable for PbS CQD PVs. With this new class of $n$-type PbS CQD film, $6 \%$ PCE has been achieved. This work is the first demonstration of PbS CQD PVs using PbS CQD ink prepared via solution-phase ligand exchange, and the trend of $\mathrm{PbS} C \mathrm{CQD}$ research has begun to change from solid-state to solution-phase ligand exchange.

\subsection{Flat Energy Landscape and High Packing Density in Quantum Dots}

In CQD solids, the inhomogeneous energy distribution is an important problem limiting the further improvement of device performances [38-40]. Poor monodispersity, disordered packing, and aggregation of CQDs can produce additional energy distribution at the band edge including both conduction and valance band [41-45]. Additionally, energetic inhomogeneity arises from the solid-state ligand exchange procedure [42]. The solid-state ligand exchange has disadvantages, such as insufficient ligand exchange, CQD fusion, and remained organic debris. The solution-phase ligand exchange approach can be considered as a solution to overcome these problems. However, previous CQD ink-based PVs have not yet outperformed the conventional solid-stated ligand-exchanged CQD PVs [38]. The lesser performance of CQD ink-based PVs originates from the counter-ions, which are essential for colloidal stability under polar solvents, and the residual counter-ions in CQD film can hinder charge transport [34,35]. Counter ions can be removed by a post-annealing process; however, halide ligands on the CQD surface also can be damaged during this process, resulting in the poor surface passivation and aggregation of CQDs [34]. Therefore, the CQD PV performance can be improved by the removal of unwanted counter ions before film deposition. Sargent et al. suggested a new solution-phase ligand exchange process using lead halide and ammonium acetate salts [46]. The hybrid PbS CQD ink exhibited increases in both the incorporation of halide ligands on the PbS CQD surface, as well as the elimination of native oleic acid ligand residuals remaining in the resultant PbS CQD solutions [46]. This new PbS CQD ink demonstrated multiple benefits, including reduced band tails that improved the open-circuit voltage $\left(V_{\mathrm{OC}}\right)$, better carrier transport, and improved light absorption [46]. The densified halide ligands also exhibit improved surface passivation, allowing 
thicker PbS CQD film, which is beneficial for light harvesting. These benefits enable the fabrication of PbS CQD PVs with a certified PCE of $11.28 \%$.

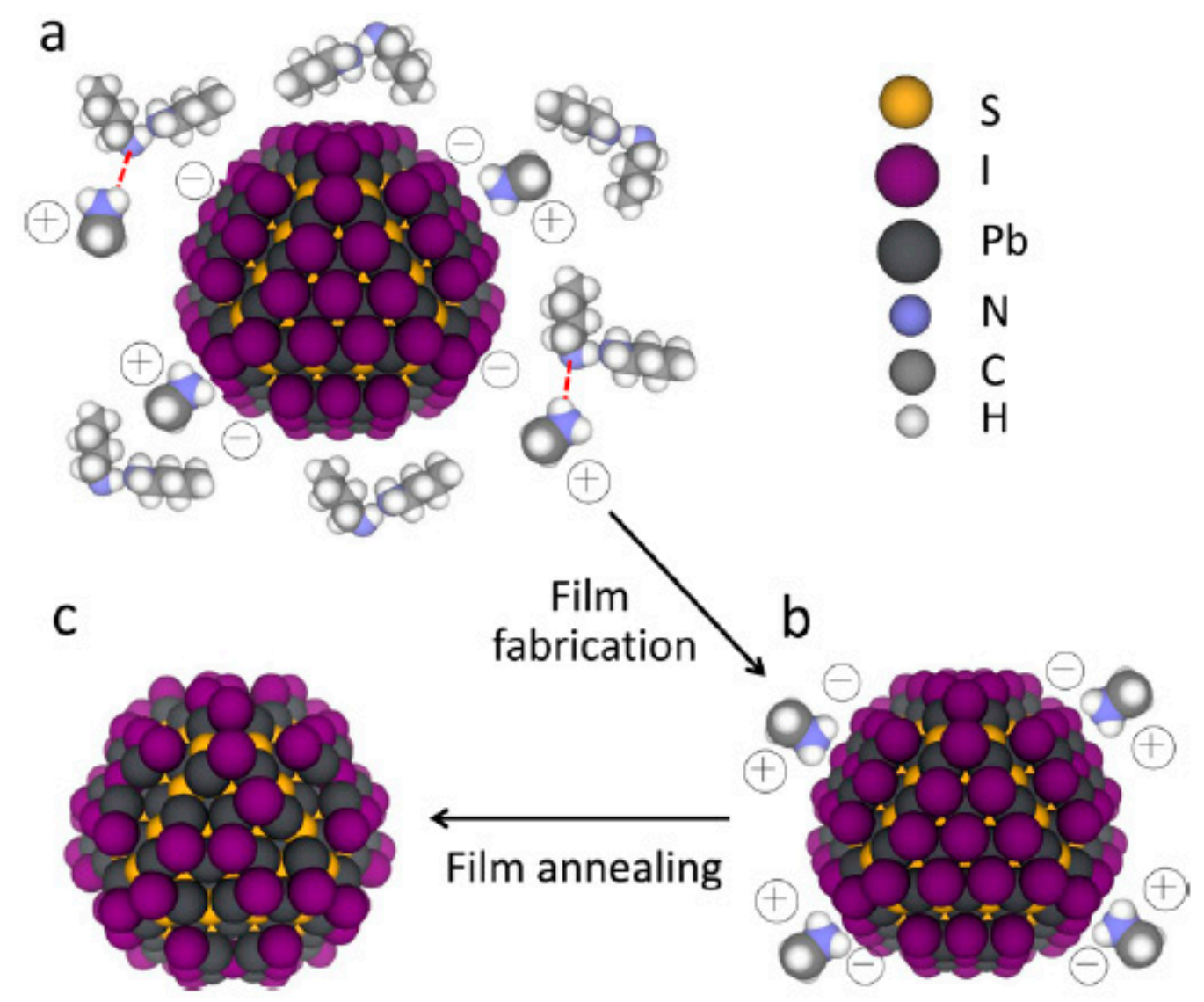

Figure 6. Schematic of surface ion distribution of PbS CQDs. (a) The PbS CQDs prepared after ligand exchange with iodide in butylamine. Iodide anions attached on the PbS CQD surface are surrounded by methylammonium counter cations. Methylammonium can be removed from the surface by reaction with butylamine. (b) As-deposited PbS CQD films. The counter ions residing on the CQD surface to keep neutrality of charge. (c) Annealed PbS CQD film. The ion pairs are removed, but most of the iodide ligands remain on the CQD surface. Reprinted from reference [34]. Copyright 2014 American Chemical Society.

\subsection{Tuning Reactivity of Ligands}

The energetic disorder caused by the increase of $\mathrm{PbS} C Q D$ polydispersity restricts the $V_{\mathrm{OC}}$ and resultantly low PCE in PbS CQD PVs. This energy broadening even becomes wider during PbS CQD ligand exchange and thin film fabrication resulting in large energy loss of CQD PVs over the Shockley-Queisser limit $\left(\mathrm{E}_{\text {loss }}=\mathrm{qV}_{\mathrm{SQ}}-\mathrm{qV}_{\mathrm{OC}}\right)$ and low $V_{\mathrm{OC}}$ value. The $\mathrm{E}_{\text {loss }}$ of crystalline silicon and perovskite $\mathrm{PVs}$ is in the range of 0.1 to $0.2 \mathrm{eV}$, and this mainly originates from trap recombination losses, leading to destroyed $V_{\mathrm{OC}}[47,48]$. However, the general $\mathrm{E}_{\text {loss }}$ in the PbSCQD PVs is approximately $0.4 \mathrm{eV}$, mainly contributed by $\mathrm{PbS} C Q D$ polydispersity after the ligand exchange process [46]. The replacement of the long-chain ligands by the short-chain conductive ligands can lead to a stripped CQD surface, resulting in CQD fusion $[29,49]$. The polydispersity of PbS CQDs can be reduced by controlling the reactivity of ligands during the ligand exchange process [50]. For this purpose, ammonium acetate (AA, reactive species) and tetrabutylammonium acetate (TBAA, less reactive species) mixtures were employed for the solution-phase ligand exchange, and these simultaneously provided improved surface passivation and charge transport with preserved the homogeneity of the PbS CQDs. The less reactive TBAA ligand can preserve a small portion of organic ligand on the CQD surface for preventing $\mathrm{PbS}$ CQD fusion and etching. The optimized PbS CQD PVs prepared by this approach exhibits 
improved device performance compared to conventional CQD PVs $(10.1 \% \rightarrow 10.9 \%)$ with a remarkably enhanced $V_{\mathrm{OC}}$ value $(0.61 \rightarrow 0.7 \mathrm{~V}$, as shown in Figure $7 \mathrm{a}, \mathrm{b})$.
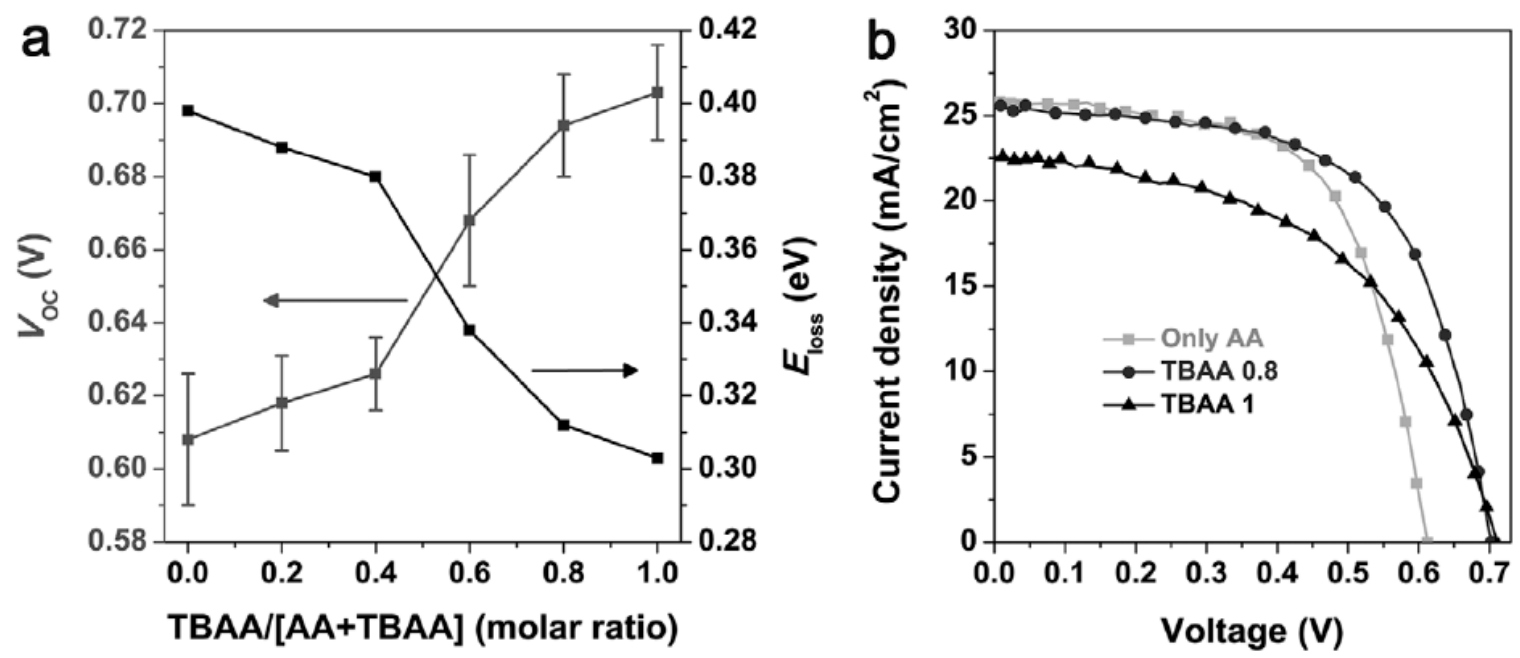

Figure 7. Photovoltaic performance depending on ratio of used ligand species (ammonium acetate (AA) and tetrabutylammonium acetate (TBAA)) in solution-phase ligand exchange. (a) Trends of $\mathrm{V}_{\mathrm{OC}}$ and $\mathrm{E}_{\text {loss }}$ observed in PbS CQD photovoltaics according to ligand ratio. (b) J-V curves of PbS CQD PVs with various ligand blend ratios. Reprinted from reference [50]. Copyright 2017 Advanced Materials.

\subsection{Improved Diffusion Length of Quantum Dot Film by Matrix Approach}

Recently, research on composition-matched matrices to improve carrier mobility has focused on CQDs [51]. Especially, metal halide perovskite materials exhibit well lattice matching matrices with CQDs, showing improved CQD emission performance [52]. Based on these results, researchers have deduced that the limitations in the diffusion length of photocarrier and deterioration of $V_{\mathrm{OC}}$ could be tackled by spatial changes in the matrix structure generating from the CQD film fabrications. It has been reported that photocarrier transfer at the CQD film is crucially affected by thickness of matrix in terms of electron tunneling and resonance energy transfer [41,52-54]. Non-uniformity of the matrix results in the increase of structural and energy disturbances and the decrease of diffusion lengths within CQD thin films and devices [41,47,55-57].

To solve this problem, Sargent et al. devised a 2D matrix strategy using the perovskites to prevent the formation of a thick matrix, which can be formed during film solidification [58]. It aimed to extend the diffusion length of photocarrier in PbS CQD film through the matrix refinement, thereby limiting the $\mathrm{PbI}_{2}$ matrix components to $2 \mathrm{D}$ materials produced from a $\mathrm{PbI}_{2}$ and hybrid amine coordination complex, which is a similar phenomenon in 2D perovskite synthesis [59,60]. It suggests that the hybrid amine coordinate complex can produce high-quality $2 \mathrm{D}$ inorganic matrices that program inter-nanoparticle spacing on an atomic scale, thereby improving the robustness of the PbS CQD packing density and uniformity, leading to reduced energy disturbances.

As a result, this study demonstrates a matrix engineering approach that can largely improve the diffusion length of photocarrier in PbS CQD solids and enhances the energetic disorder of densely-packed PbS CQD thin films, resulting in record-breaking performances on increasing the thickness of the PbS CQD thin films. This matrix-based CQD material engineering strategies can be extended to a wide range of PbS CQD application fields, including light-emitting diodes, photodetector, and field effect transistor.

\subsection{Acid-Assisted Ligand Exchange for Infrared Quantum Dots}

Large-size (small bandgap) PbS CQD can provide a chance to harvest an infrared (IR) region solar spectrum. The light absorption onset of well-known photoactive materials including metal halide 
perovskite, organic dye, crystalline silicon, is limited under $1100 \mathrm{~nm}$. Therefore, the large-size PbS CQD solids can be a promising platform to realize multijunction or IR optoelectronics. Recent advance in solution ligand exchange suggest that the CQD polydispersity can be minimized via engineering of ligand reactivity $[34,46]$. However, these approaches are undesired for a large-size IR CQD film where the charge carrier transport become more important. Undesirable organic residues on the CQD surface can lead to a loosely-packed CQD film morphology resulting in poor charge transport and device performance [61-63].

To address this issue, an acid-assisted solution-phase ligand exchange was suggested to promote the release of the long-chain original ligands, leading to the attainment of compact PbS CQD thin films and enhanced mobility. Sargent et al. found that the employment of hydroiodic acid (HI) can facilitate dense PbS CQD film formation aid by proton and iodide donation resulting in full removal of organic residues and better CQD passivation [63]. It is demonstrated that HI-treated dense IR PbS CQD films show higher carrier mobility than that of convention ligand-exchanged CQD film (Figure 8a,b). In the IR CQD PV, the device shows a Si-filtered PCE of $\sim 0.9 \%$ and a high external quantum efficiency (EQE) of $50 \%$ at $1550 \mathrm{~nm}$, whereas the conventional device (without HI treatment) exhibits less than a Si-filtered PCE of $\sim 0.6 \%$ with a lower EQE of $30 \%$ [63]. This study suggests a new way to produce high-quality IR PbS CQD films leading to efficient charge transport, which is one of the essential factors for realizing IR optoelectronic devices.
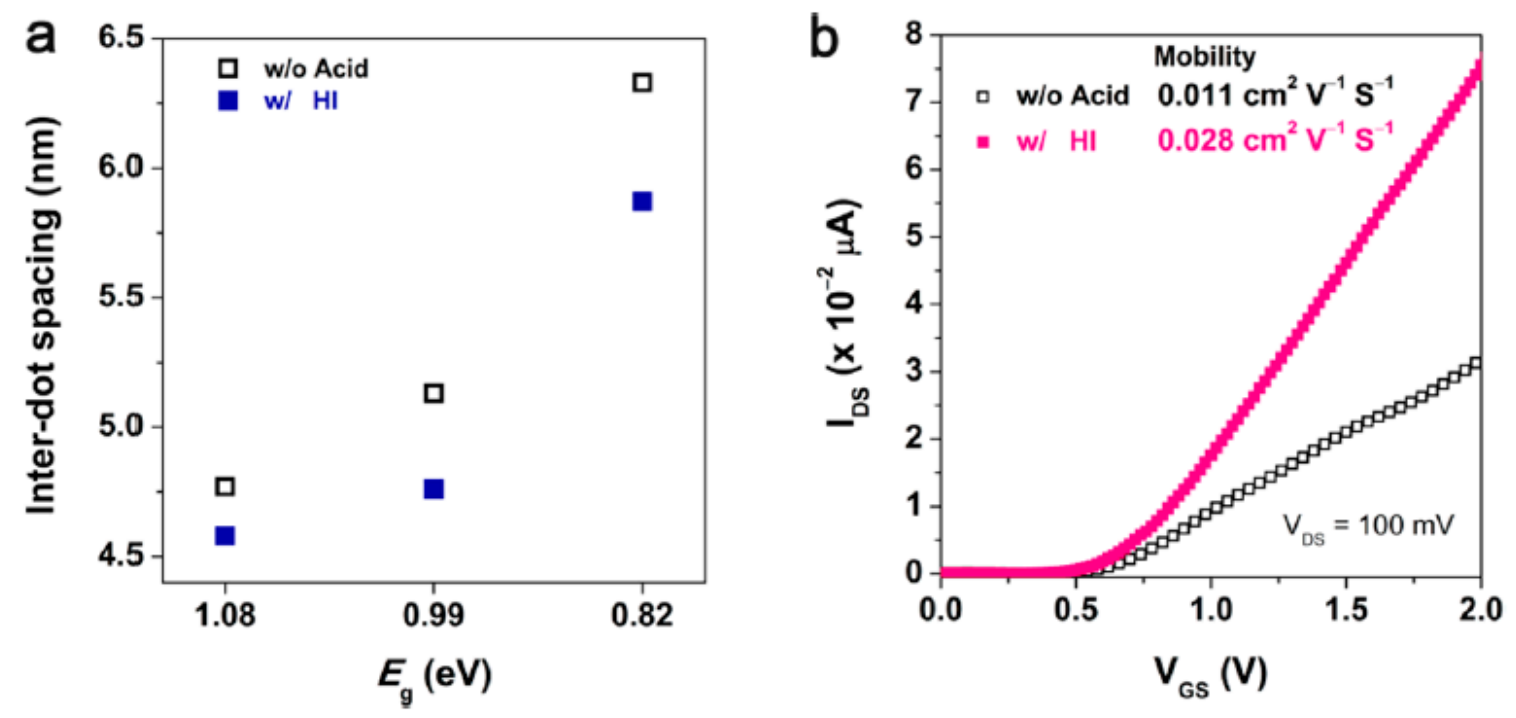

Figure 8. Film geometry and charge transfer characteristics of infrared (IR) PbS CQD films treated with hydroiodic acid (HI) during solution-phase ligand exchange process. (a) Interdot spacing of PbS CQD film according to $\mathrm{HI}$ treatment. (b) Mobility of PbS CQD films characterized by field-effect transistor (FET) measurements. Reprinted from reference [63]. Copyright 2018 American Chemical Society.

\subsection{A Facet-Specific Quantum Dot Passivation Strategy for Infrared Quantum Dots}

$\mathrm{PbSCQDs}$ show size- and facet-dependent properties, and the diameter of PbS CQDs must become larger to harvest the IR region solar spectrum. However, these PbS CQDs exhibit a large amount of non-polar (100) facets on their surface, which is less detectable in small-diameter PbS CQDs. In the solution-phase ligand exchange methods optimized for small-diameter PbS CQDs, the ligand exchange of native oleic acid ligands to lead halide anions occur mainly on the polar (111) facets of Pb-abundant sites with the assistance of ammonium $\mathrm{NH}_{4}{ }^{+}$cations [64]. However, this approach is not applicable for large-diameter PbS CQDs showing a large fraction of (100) facets [46,61]. These large-diameter PbS CQDs are easily aggregated and even fuse during the ligand exchange step because on (100) facets, the oleic acid ligands are easily removed by polar solvents. 
Very recently, a new solution-phase ligand exchange process to passivate (100) facet has been suggested by the careful selection of metal cations and anions. By replacing the ammonium acetate with sodium acetate in a ligand exchange process, (100) facet passivation can be achieved by $\mathrm{Na}$ owing to the proper cation size and dissociation constant of Na (Figure 9a) $[65,66]$. This approach protects IR-CQDs from aggregation during the solution-phase ligand exchange, leading to improved stability and enhanced photophysical properties of the resultant PbS CQDs. The Na-passivated IR CQD solids prepared via this approach demonstrated the improvement of PCE values under the full solar spectrum ( $33 \%$ of enhancement) and silicon-filtered solar spectrum ( $48 \%$ of enhancement) as shown in Figure 9b,c [66].

(a)

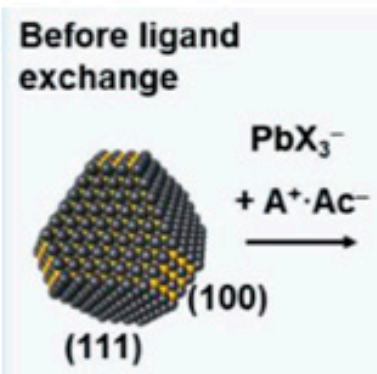

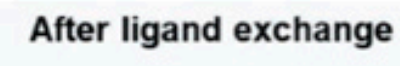

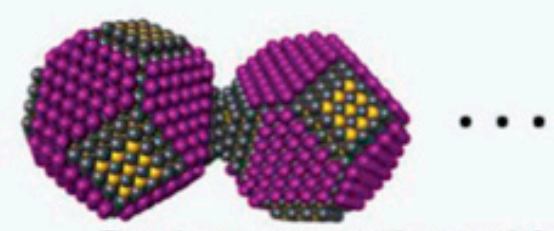

Random aggregation and fusion by unpassivated $(100)$ facets
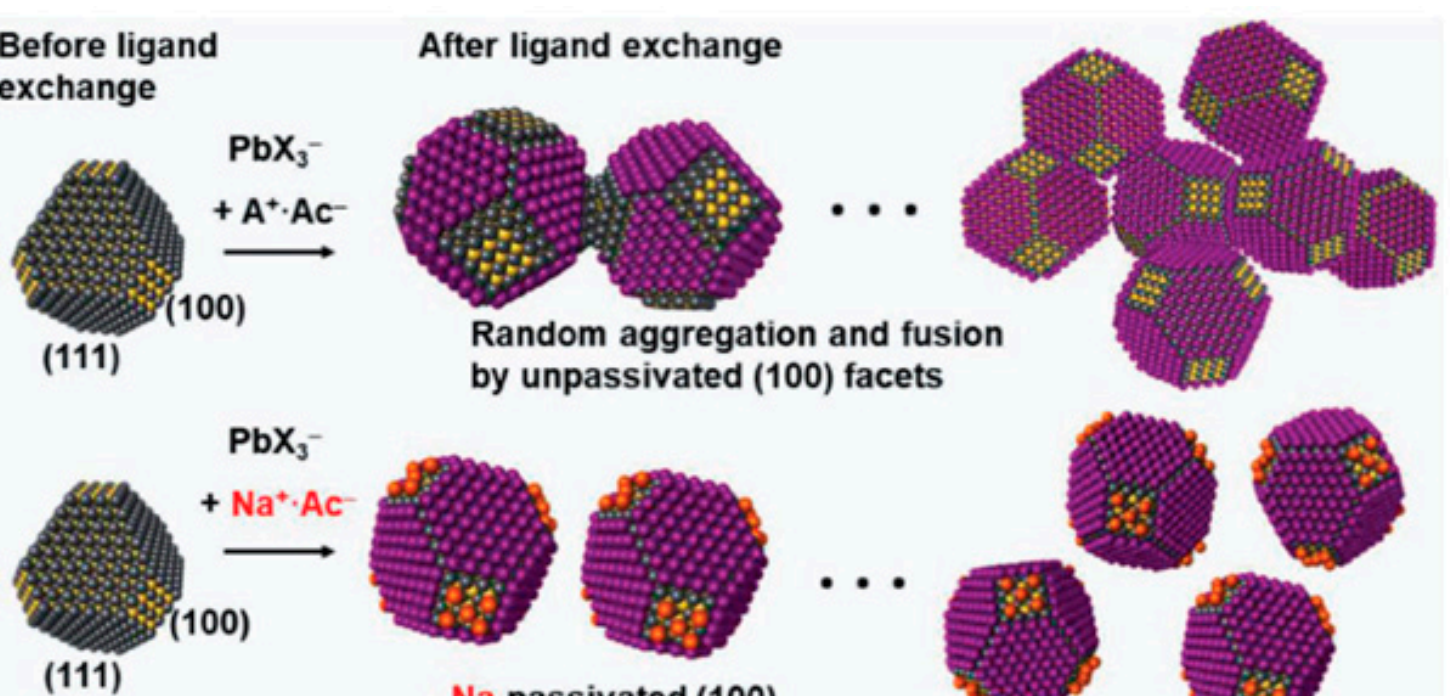

(111)

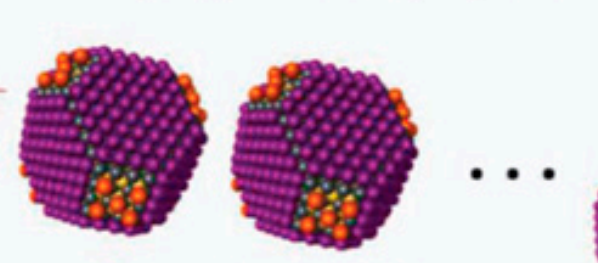

Na-passivated (100)
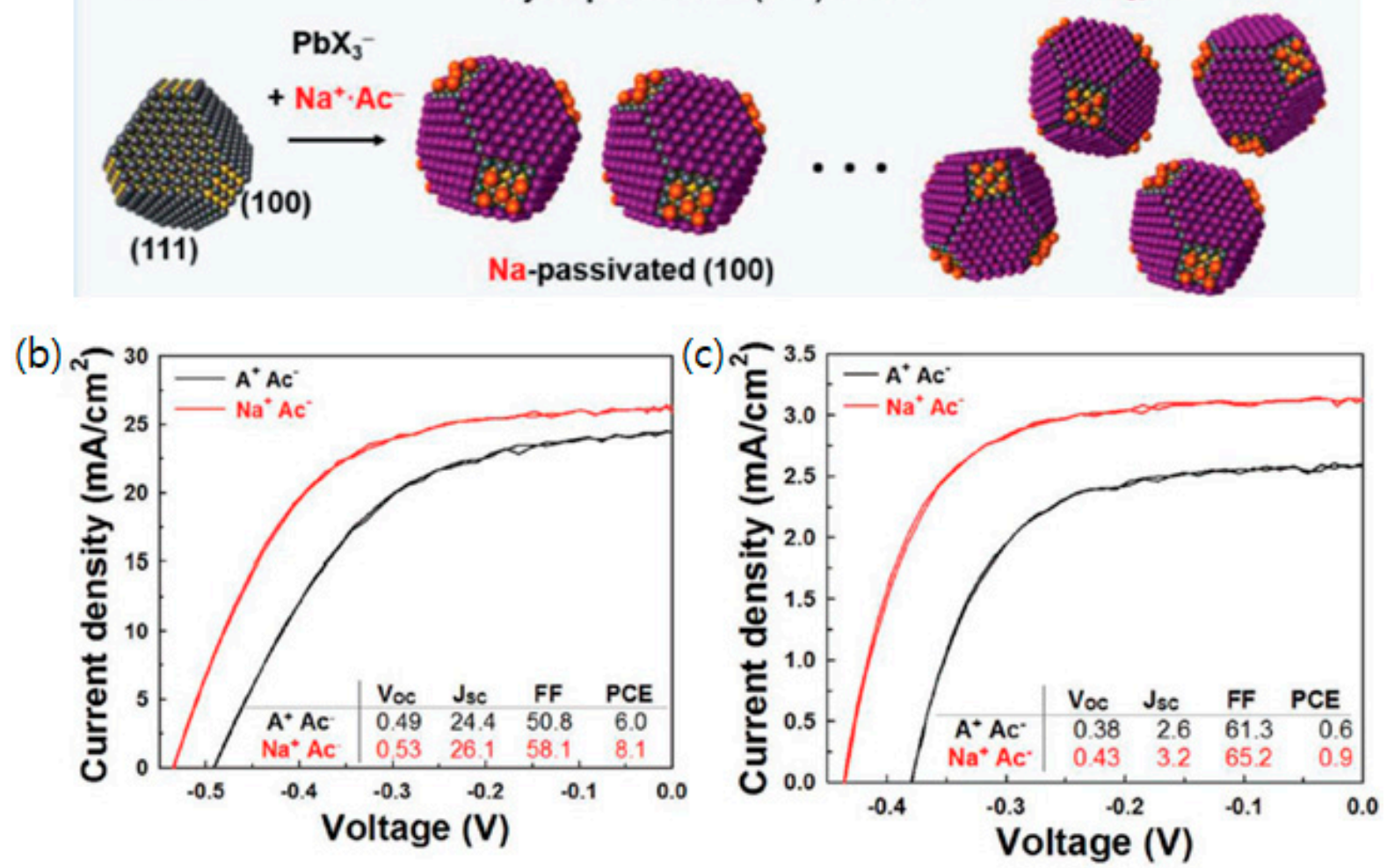

Figure 9. (a) Schematic illustration of facet-specific ligand passivation for IR PbS CQDs compared to conventional ligand exchange process. (b) J-V characteristics of IR CQD PVs with different ligand species under AM 1.5 illumination. (c) crystalline silicon filtered J-V characteristics of corresponding IR CQD PVs. Reprinted from reference [66]. Copyright 2019 Advanced Materials.

\section{Conclusions}

We summarize recent achievements in PbS CQD ligand exchange procedures for solar cell applications. The PbS CQDs are passivated by long-chain organic ligands to produce solubility in non-polar solvents. The replacement of these long-chain ligands to short-chain ligands is essential to realize PbS CQD optoelectronics. In early studies, such ligand exchanges are mainly carried out in solid-state based on layer-by-layer deposition processes. However, solid-state ligand exchange methods 
show a heavy waste of PbS CQD ink, ligand loss, and time consumption limitations. Solution-phase ligand exchange processes can compensate for these limitations arising from the solid-state ligand exchange process, and recent high device performances in PbS CQD PVs have been achieved by this approach. Although impressive progress in the solution-phase ligand exchange process is being made, further intensive studies are required in this field to realize efficient IR CQD solar cells that utilize beyond the $1600 \mathrm{~nm}$ IR solar spectrum. Considering the versatile applicability of $\mathrm{PbS}$ CQDs, such progress is potentially promising for further applications including multijunction and IR specialized optoelectronics.

Author Contributions: H.R.Y. and J.Y.P. contributed equally. All authors contributed to writing and revising the manuscript. J.C. and Y.K. supervised the manuscript. H.R.Y. and J.Y.P. conceived the idea and designed main structure of the manuscript. D.H.L. supported a literature survey and preparation of partial part of manuscript. All authors have read and agreed to the published version of the manuscript.

Funding: This work was supported by POSCO Science Fellowship of POSCO TJ Park Foundation, and by the National Research Foundation of Korea (NRF), grant funded by the Korea government (MSIT) (NRF-2019R1G1A1099673). This work was also supported by the Korea Institute of Energy Technology Evaluation and Planning (KETEP) and the Ministry of Trade, Industry \& Energy (MOTIE) of the Republic of Korea (No. 20173010013200).

Conflicts of Interest: The authors declare no conflicts of interest.

\section{References}

1. Ekimov, A.I.; Onushchenko, A.A. Quantum size effect in three-dimensional microscopic semiconductor crystals. JETP Lett. 1982, 34, 345-349.

2. Brus, L.E. A simple model for the ionization potential, electron affinity, and aqueous redox potentials of small semiconductor crystallites. J. Chem. Phys. 1983, 79, 5566-5571. [CrossRef]

3. Klimov, V.I. Spectral and dynamical properties of multiexcitons in semiconductor nanocrystals. Annu. Rev. Phys. Chem. 2007, 58, 635-673. [CrossRef] [PubMed]

4. Pandey, A.; Guyot-Sionnest, P. Slow electron cooling in colloidal quantum dots. Science 2008, 322, 929-932. [CrossRef] [PubMed]

5. Niemal, M.; Norris, D.J.; Kuno, M.; Bawendi, M.G.; Efros, A.L.; Rosen, M. Observation of the "dark exciton" in CdSe quantum dots. Phys. Rev. Lett. 1995, 75, 37223731.

6. Choi, J.J.; Wenger, W.N.; Hoffman, R.S.; Lim, Y.-F.; Luria, J.; Jasieniak, J.; Marohn, J.A.; Hanrath, T. Solution-Processed Nanocrystal Quantum Dot Tandem Solar Cells. Adv. Mater. 2011, 23, 3144-3148. [CrossRef] [PubMed]

7. Zhitomirsky, D.; Voznyy, O.; Levina, L.; Hoogland, S.; Kemp, K.W.; Ip, A.H.; Thon, S.M.; Sargent, E.H. Engineering Colloidal Quantum Dot Solids within and beyond the Mobility-Invariant Regime. Nat. Commun. 2014, 5, 3803. [CrossRef]

8. Johnston, K.W.; Pattantyus-Abraham, A.G.; Clifford, J.P.; Myrskog, S.H.; MacNeil, D.D.; Levina, L.; Sargent, E.H. Schottky-Quantum Dot Photovoltaics for Efficient Infrared Power Conversion. Appl. Phys. Lett. 2008, 92, 151115. [CrossRef]

9. Ma, W.; Luther, J.M.; Zheng, H.; Wu, Y.; Alivisatos, A.P. Photovoltaic Devices Employing Ternary PbS $x$ Se1-x Nanocrystals. Nano Lett. 2009, 9, 1699-1703. [CrossRef]

10. Tang, J.; Brzozowski, L.; Barkhouse, A.; Wang, X.; Debnath, R.; Wolowiec, R.; Palmiano, E.; Levina, L.; Pattantyus-Abraham, A.G.; Jamakosmanovic, D.; et al. Quantum Dot Photovoltaics in the Extreme Quantum Confinement Regime: The Surface-Chemical Origins of Exceptional Air- and Light-Stability. ACS Nano 2010, 2, 869-878. [CrossRef]

11. Moreels, L.; Fritzinger, B.; Martins, J.C.; Hens, Z. Surface Chemistry of Collodial PbSe Nanocrystals. J. Am. Chem. Soc. 2008, 130, 15081-15086. [CrossRef] [PubMed]

12. Konstantatos, G.; Levina, L.; Fisher, A.; Sargent, E.H. Engineering the Temporal Response of Photoconductive Photodetectors via Selective Introduction of Surface Trap States. Nano Lett. 2008, 8, 1446-1450. [CrossRef] [PubMed]

13. Konstantatos, G.; Sargent, E.H. PbS Colloidal Quantum Dot Photoconductive Photodetectors: Transport, Traps and Gain. Appl. Phys. Lett. 2007, 91, 173505. [CrossRef] 
14. Fan, D.B.; Thomas, P.J.; O’Brien, P. Pyramidal Lead Sulfide Crystallites with High Energy $\{113\}$ Facets. J. Am. Chem. Soc. 2008, 130, 10892-10894. [CrossRef]

15. Warner, J.H.; Cao, H. Shape Control of PbS Nanocrystals Using Multiple Surfactants. Nanotechnology 2008, 19, 305605. [CrossRef]

16. Joseph, M.L.; Gao, J.; Lloyd, M.T.; Semonin, O.E.; Beard, M.C.; Arthur Nozik, A.J. Stability assessment on a $3 \%$ bilayer $\mathrm{PbS} / \mathrm{ZnO}$ quantum dot heterojunction solar cell. Adv. Mater. 2010, 22, 3704-3707.

17. Luther, J.M.; Law, M.; Song, Q.; Beard, M.C.; Nozik, A.J. Structural, Optical, and Electrical Properties of Self-Assembled Films of PbSe Nanocrystals Treated with 1,2-Ethanedithiol. ACS Nano 2008, 2, 271-280. [CrossRef]

18. Luther, J.M.; Law, M.; Song, Q.; Reese, M.O.; Beard, M.C.; Ellingson, R.J.; Nozik, A.J. Schottky Solar Cells Based on Colloidal Nanocrystal Films. Nano Lett. 2008, 8, 3488-3492. [CrossRef]

19. Law, M.; Beard, M.C.; Choi, S.; Luther, J.M.; Hanna, M.C.; Nozik, A.J. Determining the Internal Quantum Efficiency of PbSe Nanocrystal Solar Cells with the Aid of an Optical Model. Nano Lett. 2008, 8, 3904-3910. [CrossRef]

20. Zarghami, M.H.; Markelle Gibbs, Y.L.; Gebremichael, E.; Webster, C.; Law, M. p-Type PbSe and PbS Quantum Dot Solids Prepared with Short-Chain Acids and Diacids. ACS Nano 2010, 4, 2475-2485. [CrossRef]

21. Gur, I.; Fromer, N.A.; Geier, M.L.; Alivisatos, A.P. Air-stable all-inorganic nanocrystal solar cells processed from solution. Science 2005, 310, 462-465. [CrossRef] [PubMed]

22. Ip, A.H.; Thon, S.M.; Hoogland, S.; Voznyy, O.; Zhitomirsky, D.; Debnath, R.; Levina, L.; Rollny, L.R.; Carey, G.H.; Fischer, A.; et al. Hybrid passivated colloidal quantum dot solids. Nat. Nano 2012, 79, 577-582.

23. Ning, Z.; Voznyy, O.; Pan, J.; Hoogland, S.; Adinolfi, V.; Xu, J.; Li, M.; Kirmani, A.R.; Sun, J.-P.; Minor, J.; et al. Air-stable n-type colloidal quantum dot solids. Nat. Mater. 2014, 13, 822-828. [CrossRef] [PubMed]

24. Zhang, J.; Gao, J.; Church, C.P.; Miller, E.M.; Luther, J.M.; Klimov, V.I.; Beard, M.C. PbSe quantum dot solar cells with more than 6\% efficiency fabricated in ambient atmosphere. Nano Lett. 2014, 14, 6010-6015. [CrossRef] [PubMed]

25. Crisp, R.W.; Kroupa, D.M.; Marshall, A.R.; Miller, E.M.; Zhang, J.; Beard, M.C.; Luther, J.M. Metal halide solid-state surface treatment for high efficiency $\mathrm{PbS}$ and PbSe QD solar cells. Sci. Rep. 2015, 5, 9945. [CrossRef] [PubMed]

26. Lan, X.; Voznyy, O.; Kiani, A.; García de Arquer, F.P.; Abbas, A.S.; Kim, G.-H.; Liu, M.; Yang, Z.; Walters, G.; $\mathrm{Xu}, \mathrm{J}$; et al. Passivation using molecular halides increases quantum dot solar cell performance. Adv. Mater. 2016, 28, 299-304. [CrossRef] [PubMed]

27. Lan, X.; Voznyy, O.; García de Arquer, F.P.; Liu, M.; Xu, J.; Proppe, A.; Walters, G.; Fan, F.; Tan, H.; Liu, M.; et al. $10.6 \%$ Certified Colloidal Quantum Dot Solar Cells via Solvent-Polarity-Engineered Halide Passivation. Nano Lett. 2016, 16, 4630-4634. [CrossRef]

28. Talapin, D.V.; Murray, C.B. PbSe Nanocrystals Solids for n- and p-Channel Thin Film Field-Effect Transistors. Science 2005, 310, 86-89. [CrossRef]

29. Wang, X.; Koleilat, G.; Tang, J.; Liu, H.; Kramer, I.J.; Debnath, R.; Brzozowski, L.; Barkhouse, D.A.R.; Levina, L.; Hoogland, S.; et al. Tandem Colloidal Quantum Dot Solar Cells Employing a Graded Recombination Layer. Nat. Photonics 2011, 5, 480-484. [CrossRef]

30. Ning, Z.; Zhitomirsky, D.; Adinolfi, V.; Sutherland, B.; Xu, J.; Voznyy, O.; Maraghechi, P.; Lan, X.; Hoogland, S.; Ren, Y.; et al. Graded Doping for Enhanced Colloidal Quantum Dot Photovoltaics. Adv. Mater. 2013, 25, 1719-1723. [CrossRef]

31. Tang, J.; Liu, H.; Zhitomirsky, D.; Hoogland, S.; Wang, X.; Furukawa, M.; Levina, L.; Sargent, E.H. Quantum Junction Solar Cells. Nano Lett. 2012, 12, 4889-4894. [CrossRef] [PubMed]

32. Zhitomirsky, D.; Furukawa, M.; Tang, J.; Stadler, P.; Hoogland, S.; Voznyy, O.; Liu, H.; Sargent, E.H. N-Type Colloidal-Quantum-Dot Solids for Photovoltaics. Adv. Mater. 2012, 24, 6181-6185. [CrossRef] [PubMed]

33. Voznyy, O.; Zhitomirsky, D.; Stadler, P.; Ning, Z.; Hoogland, S.; Sargent, E.H. A Charge-Orbital Balance Picture of Doping in Colloidal Quantum Dot Solids. ACS Nano 2012, 6, 8448-8455. [CrossRef] [PubMed]

34. Ning, Z.; Dong, H.; Zhang, Q.; Voznyy, O.; Sargent, E.H. Solar Cells Based on Inks of n-Type Colloidal Quantum Dots. ACS Nano 2014, 8, 10321-10327. [CrossRef]

35. Kovalenko, M.V.; Scheele, M.; Talapin, D.V. Colloidal Nanocrystals with Molecular Metal Chalcogenide Surface Ligands. Science 2009, 324, 1417-1420. [CrossRef] 
36. Kovalenko, M.V.; Bodnarchuk, M.I.; Zaumseil, J.; Lee, J.-S.; Talapin, D.V. Expanding the Chemical Versatility of Colloidal Nanocrystals Capped with Molecular Metal halcogenide Ligands. J. Am. Chem. Soc. 2010, 132, 10085-10092. [CrossRef]

37. Talapin, D.V.; Lee, J.-S.; Kovalenko, M.V.; Shevchenko, E.V. Prospects of Colloidal Nanocrystals for Electronic and Optoelectronic Applications. Chem. Rev. 2010, 110, 389-458. [CrossRef]

38. Pejova, B.; Abay, B. Nanostructured CdSe films in low size-quantization regime: Temperature dependence of the band gap energy and sub-band gap absorption tails. J. Phys. Chem. C 2011, 115, 23241-23255. [CrossRef]

39. Pejova, B.; Abay, B.; Bineva, I. Temperature dependence of the band-gap energy and sub-band-gap absorption tails in strongly quantized ZnSe nanocrystals deposited as thin films. J. Phys. Chem. C 2010, 114, 15280-15291. [CrossRef]

40. Zhitomirsky, D.; Kramer, I.J.; Labelle, A.J.; Fischer, A.; Debnath, R.; Pan, J.; Bakr, O.M.; Sargent, E.H. Colloidal quantum dot photovoltaics: The effect of polydispersity. Nano Lett. 2012, 12, 1007-1012. [CrossRef]

41. Guyot-Sionnest, P. Electrical transport in colloidal quantum; dot films. J. Phys. Chem. Lett. 2012, 3, 1169-1175. [CrossRef] [PubMed]

42. Sa-Yakanit, V.; Glyde, H.R. Urbach tails and disorder. Comments Condens. Matter Phys. 1987, 13, 35-48.

43. Erslev, P.T.; Chen, H.Y.; Gao, J.; Beard, M.C.; Frank, A.J.; van de Lagemaat, J.; Johnson, J.C.; Luther, J.M. Sharp exponential band tails in highly disordered lead sulfide quantum dot arrays. Phys. Rev. B 2012, 86, 155313-155316. [CrossRef]

44. Kagan, C.R.; Murray, C.B. Charge transport in strongly coupled quantum dot solids. Nat. Nanotech 2015, 10, 1013-1026. [CrossRef]

45. Yang, Z.; Janmohamed, A.; Lan, X.; de Arquer, F.P.G.; Voznyy, O.; Yassitepe, E.; Kim, G.; Ning, Z.; Gong, X.; Comin, R.; et al. Colloidal quantum dot photovoltaics enhanced by perovskite shelling. Nano Lett. 2015, 15, 7539-7543. [CrossRef]

46. Liu, M.; Voznyy, O.; Sabatini, R.; de Arquer, F.P.G.; Munir, R.; Balawi, A.H.; Lan, X.; Fan, F.; Walters, G.; Kirmani, A.R.; et al. Hybrid organic-inorganic inks flatten the energy landscape in colloidal quantum dot solids. Nature Mater 2017, 16, 258-263. [CrossRef]

47. Chuang, C.-H.M.; Maurano, A.; Brandt, R.E.; Hwang, G.W.; Jean, J.; Buonassisi, T.; Bulović, V.; Bawendi, M.G. Open-circuit voltage deficit, radiative sub-bandgap states, and prospects in quantum dot solar cells. Nano Lett. 2015, 15, 3286-3294. [CrossRef]

48. Polman, A.; Knight, M.; Garnett, E.C.; Ehrler, B.; Sinke, W.C. Photovoltaic materials: Present efficiencies and future challenges. Science 2016, 352, aad4424. [CrossRef]

49. Carey, G.H.; Kramer, I.J.; Kanjanaboos, P.; Moreno-Bautista, G.; Voznyy, O.; Rollny, L.; Tang, J.A.; Hoogland, S.; Sargent, E.H. Electronically active impurities in colloidal quantum dot solids. ACS Nano 2014, 8, 11763-11769. [CrossRef]

50. Jo, J.W.; Kim, Y.; Choi, J.; Pelayo García de Arquer, F.; Walters, G.; Sun, B.; Ouellette, O.; Kim, J.; Proppe, A.H.; Quintero-Bermudez, R.; et al. Enhanced Open-Circuit Voltage in Colloidal Quantum Dot Photovoltaics via Reactivity-Controlled Solution-Phase Ligand Exchange. Adv. Mater. 2017, 29, 1703627. [CrossRef]

51. Dolzhnikov, D.S.; Zhang, H.; Jang, J.; Son, J.S.; Panthani, M.G.; Shibata, T.; Chattopadhyay, S.; Talapin, D.V. Composition-matched molecular 'solders' for semiconductors. Science 2015, 347, 425-428. [CrossRef] [PubMed]

52. Ning, Z.; Gong, X.; Comin, R.; Walters, G.; Fan, F.; Voznyy, O.; Yassitepe, E.; Buin, A.; Hoogland, S.; Sargent, E.H. Quantum-dot-in-perovskite solids. Nature 2015, 523, 324-328. [CrossRef] [PubMed]

53. Kagan, C.R.; Lifshitz, E.; Sargent, E.H.; Talapin, D.V. Building devices from colloidal quantum dots. Science 2016, 353, aac5523. [CrossRef] [PubMed]

54. Gilmore, R.H.; Lee, E.M.Y.; Weidman, M.C.; Willard, A.P.; Tisdale, W.A. Charge carrier hopping dynamics in homogeneously broadened PbS quantum dot solids. Nano Lett. 2017, 17, 893-901. [CrossRef] [PubMed]

55. Ip, A.H.; Kiani, A.; Kramer, I.J.; Voznyy, O.; Movahed, H.F.; Levina, L.; Adachi, M.M.; Hoogland, S.; Sargent, E.H. Infrared colloidal quantum dot photovoltaics via coupling enhancement and agglomeration suppression. ACS Nano 2015, 9, 8833-8842. [CrossRef]

56. Carey, G.H.; Levina, L.; Comin, R.; Voznyy, O.; Sargent, E.H. Record charge carrier diffusion length in colloidal quantum dot solids via mutual dot-to-dot surface passivation. Adv. Mater. 2015, 27, 3325-3330. [CrossRef] 
57. Akselrod, G.M.; Deotare, P.B.; Thompson, N.J.; Lee, J.; Tisdale, W.A.; Baldo, M.A.; Menon, V.M.; Bulović, V. Visualization of exciton transport in ordered and disordered molecular solids. Nat. Commun. 2014, 5, 4646. [CrossRef]

58. Xu, J.; Voznyy, O.; Liu, M.; Kirmani, A.R.; Walters, G.; Munir, R.; Abdelsamie, M.; Proppe, A.H.; Sarkar, A.; Garcia de Arquer, F.P.; et al. 2D matrix engineering for homogeneous quantum dot coupling in photovoltaic solids. Nat. Nanotechnol. 2018, 13, 456-462. [CrossRef]

59. Blancon, C. Extremely efficient internal exciton dissociation through edge states in layered 2D perovskites. Science 2017, 355, 1288-1292. [CrossRef]

60. Congreve, D.N.; Weidman, M.C.; Seitz, M.; Paritmongkol, W.; Dahod, N.S.; Tisdale, W.A. Tunable light-emitting diodes utilizing quantum-confined layered perovskite emitters. ACS Photonics 2017, 4, 476-481. [CrossRef]

61. Kiani, A.; Sutherland, B.R.; Kim, Y.; Ouellette, O.; Levina, L.; Walters, G.; Dinh, C.T.; Liu, M.; Voznyy, O.; Lan, X.; et al. Single-step colloidal quantum do films for infrared solar harvesting. Appl. Phys. Lett. 2016, 109, 183105. [CrossRef]

62. Fan, J.Z.; Liu, M.; Voznyy, O.; Sun, B.; Levina, L.; Quintero-Hoogland, S.; Sargent, E.H. Halide Re-Shelled Quantum Dot Inks for Infrared Photovoltaics. ACS Appl. Mater. Interfaces 2017, 9, 37536-37541. [CrossRef] [PubMed]

63. Jo, J.W.; Choi, J.; Garcia de Arquer, F.P.; Seifitokaldani, A.; Sun, B.; Kim, Y.; Ahn, H.; Fan, J.; Quintero-Bermudez, R.; Kim, J.; et al. Acid-Assisted Ligand Exchange Enhances Coupling in Colloidal Quantum Dot Solids. Nano Lett. 2018, 18, 4417-4423. [CrossRef] [PubMed]

64. Choi, H.; Ko, J.H.; Kim, Y.H.; Jeong, S. Steric-hindrance-driven shape transition in PbS quantum dots: Understanding size-dependent stability. J. Am. Chem. Soc. 2013, 135, 5278-5281. [CrossRef] [PubMed]

65. Salis, A.; Ninham, B.W. Models and mechanisms of Hofmeister effects in electrolyte solutions, and colloid and protein systems revisited. Chem. Soc. Rev. 2014, 43, 7358-7377. [CrossRef]

66. Kim, Y.; Che, F.; Jo, J.W.; Choi, J.; García de Arquer, F.P.; Voznyy, O.; Sun, B.; Kim, J.; Choi, M.J.; Quintero-Bermudez, R.; et al. A Facet-Specific Quantum Dot Passivation Strategy for Colloid Management and Efficient Infrared Photovoltaics. Adv. Mater. 2019, 31, 1805580. [CrossRef] 